\title{
El crecimiento urbano de una ciudad turística y las políticas de ordenamiento territorial. El caso de San Carlos de Bariloche y el Plan Director de 1979
}

\author{
Touristic city growth, a case study: San Carlos de Bariloche and its masterplan of 1979
}

\section{Víctor Damián Medina*}

Recibido 3 de diciembre de 2016

Aceptado: 17 de junio de 2017

\section{Resumen}

La ordenación territorial en las ciudades supone muchas veces el equilibrio de intereses encontrados entre la explotación privada de ciertos espacios y las políticas públicas de planeamiento urbano. Más aún si este equilibrio se enmarca en el crecimiento de una ciudad turística, donde el antagonismo de intereses posiblemente encuentre mayor arraigo. El hecho de que el crecimiento de Bariloche históricamente haya avanzado sobre la costa del lago Nahuel Huapi consigue situar como interrogante el rol del medio natural en las lógicas de ocupación del suelo, pero también permite dirigir la mirada hacia los instrumentos de regulación urbana que puede utilizar el Estado para intervenir en su territorio. Este artículo propone identificar los objetivos principales del Plan Director de 1979 y su expresión normativa, el Código de planeamiento de 1980, para luego analizar su instrumentación efectiva hasta la sanción del nuevo código urbano en 1995 . Se concluye que el mercado inmobiliario local define, en última instancia, el crecimiento de la ciudad: reproduce el carácter desigual y disperso de su trama espacial y torna inocuas las iniciativas estatales de planeamiento urbano.

Palabras clave: instrumentos de ordenamiento territorial, ciudades turísticas, crecimiento urbano.

\begin{abstract}
Spatial planning in cities often means the balance of interests between the private exploitation of certain public places and urban planning policies. Moreover if this balance is part of the growth of a tourist town, where antagonism of interests may find more entrenched. The fact that the urban growth of Bariloche has historically advanced on the shore of the Nahuel Huapi Lake gets put as question the role of the natural environment in the logic of land use, but also allows look towards the instruments of urban regulation that the State can use to intervene in the territory. In this direction, this article aims to identify the main objectives of the Master Plan of 1979 and its normative expression, the 1980 planning code, and then analyze its effective instrumentation until the enactment of new urban code in 1995. It is concluded that the local real estate market sets, ultimately, the growth of the city: this reproduces the unequal and dispersed nature of its spatial pattern and becomes harmless State urban planning policies.
\end{abstract}

Keywords: land use planning, urban growth, tourist cities.

\footnotetext{
* Fundación Bariloche, Departamento de Desarrollo Integrado, San Carlos de Bariloche, Río Negro, Argentina. Contacto: damianviktor@yahoo.com.ar
}

Se agradece al Consejo Nacional de Investigaciones Científicas y Técnicas (CONICET), quien financió esta investigación a través de la "Beca interna de postgrado tipo I" y "Beca interna de postgrado tipo II", ambas destinadas a la realización de estudios de doctorado.

Cómo citar: Medina, V. (2017). El crecimiento urbano de una ciudad turística y las políticas de ordenamiento territorial. El caso de San Carlos de Bariloche y el Plan Director de 1979. Revista de Urbanismo, 36, 17-32. http:// dx. doi.org/ 10.5354/ 0717-5051.2017.44368 


\section{Introducción}

Los límites político-administrativos de la ciudad, su representación en tanto jurisdicción municipal y las competencias que las autoridades locales se atribuyen a lo largo y ancho de su ejido, suelen comparecer habitualmente en múltiples descripciones que involucran a las urbes y sus fronteras territoriales. A menudo, también acompañan esta caracterización algunos elementos que hacen a la fisonomía peculiar de su espacio físico. En el caso de la ciudad turística de San Carlos de Bariloche -localizada en la Provincia de Río Negro, sobre la Patagonia norte argentina- esto podría comprender una serie de condicionamientos, climáticos y topográficos que ayudarían a definirla en su singularidad como destino de montaña. Sin embargo, esto involucraría una mirada estática sobre el territorio de la ciudad y la conformación de su espacio urbano, una mirada ajena a los procesos históricos que trazaron sus límites territoriales.

Eugenie Sánchez (1991) afirma que el espacio geográfico es considerado espacio natural cuando está puramente integrado por componentes físicoambientales sujetos a su propia dinámica y determinado por el ecosistema que lo contiene. Es un espacio todavía ajeno a las acciones de las personas y a las consecuencias de su interposición en el medio natural (Sánchez, 1991, p. 5). Adquiere sus dimensiones sociales, en cambio, cuando interviene el ser humano en el espacio físico y lo transforma en espacio producido. En estos términos, el espacio geográfico es concebido como

(...) medio en el cual se desarrolla la actividad del hombre, la acción humana y social, o sea, el marco de toda acción, relación, articulación o suceso en el que participa como variable el espacio físico y en el que desarrollan su vida y su actividad los hombres (Sánchez, 1991, p. 3).

Esta consideración que incumbe a la intervención histórica del ser humano en la naturaleza es la que se quiere tener presente al referir como espacio producido al territorio de San Carlos de Bariloche. Permite acentuar la contingencia y dinamismo de actividades y relaciones sociales practicadas en un espacio en relación con la frontera y fisonomía de los límites urbanos y rurales de los territorios, que pueden sufrir modificaciones en tanto constituyen delimitaciones físicas del espacio geográfico practicado. De tal forma, el proceso de territorialización marca los límites físicos del espacio en el que interviene el hombre en un periodo de tiempo determinado, en el que cobran trascendencia los procesos sociales y políticos de apropiación que constituyen y dan forma al territorio. Asimismo, como espacio producido, la territorialización de la ciudad comporta un conjunto de procesos, procedimientos y actores que garantizan el soporte material y de servicios de sus habitantes, donde conviven clases sociales cuyas diferencias -económicas, políticas, culturales - tienden a distribuirse y expresarse en el territorio de esta "sociedad local" (Otero, 2011).

En este entramado, el Estado participa directamente al hacerse cargo en muchas ocasiones de la inversión en obras y servicios públicos. Pero más importante aún es su papel en el establecimiento de prescripciones relativas a la ocupación del territorio y la funcionalidad (zonificación) de cada área de la ciudad, es decir, los usos permitidos y las disposiciones vinculadas con la subdivisión del territorio, el espacio permitido para construir y las normas de edificación, que inciden en el grado de explotación del suelo y las actividades que pueden desarrollarse en él. En definitiva, condiciones de explotación que, relacionadas con las actividades que se desarrollan en una ciudad y que necesitan al suelo como componente indisociable de los procesos de producción y circulación del espacio construido, habilitan la formación de rentas urbanas (Jaramillo González, 2009; Topalov, 1979). En estos términos, las rentas diferenciales que pueden ser exigidas condicionan el acceso y la desigual distribución de los grupos sociales en el territorio (Jaramillo González, 1999), exponiendo así la lógica mercantil bajo la cual las asimetrías son retraducidas en el espacio urbano (Duhau, 2013).

Un primer acercamiento a las calles de San Carlos de Bariloche permite reconocer un modo y un estilo de ocupación del espacio que suscita la atención de quien observa. La utilización del suelo en su dilatado espacio urbano permite constatar la dispersión generalizada de la población y la distribución parcial y fragmentaria de infraestructuras y servicios públicos propia de las ciudades difusas (Borja, 2007; Indovina, 2007)1. Esto, a su vez, la erige en un espacio urbano de consumo

\footnotetext{
${ }^{1} \mathrm{Y}$ en este sentido, también, la desigualdad espacial que propicia el acceso diferenciado a estos recursos (Herce, 2005).
} 
(Meethan, 1997) que, en su especificidad, invita a reflexionar acerca de las características que asume la urbanización turística y los impactos sociales y territoriales que conlleva (Matossian, 2015; Medina, 2013). El hecho de que el crecimiento de la ciudad históricamente haya avanzado sobre la costa oeste del lago Nahuel Huapi consigue instalar como interrogante el rol del medio natural en las lógicas de ocupación territorial (Medina, 2017). Pero también interroga acerca del papel del Estado local y la potestad que este tiene de definir la normativa relativa a la planificación y ordenación territorial de una ciudad y, en consecuencia, las pautas del crecimiento urbano deseado.

Lo que aquí se postula es que la dinámica propia de la urbanización capitalista termina definiendo la dirección de la ocupación y el crecimiento de las ciudades, condicionando incluso las prescripciones urbanas que, más que regularla, tienden a acompañar su lógica. En el caso de Bariloche el sostenimiento de este aserto descansa en su particular atractivo turístico, que fija las lógicas de ocupación territorial. En esta dirección, el análisis del Plan Director de 1979 permitirá dilucidar las contradicciones inherentes al crecimiento urbano de ciudades turísticas como Bariloche y los valores naturales que ostentan, ya que al tiempo que dinamizan su economía también involucran intereses inmobiliarios que limitan las políticas de planeamiento. Los indicadores urbanísticos y los usos del suelo que el Plan estableció como instrumentos de ordenamiento territorial constituyeron un límite inédito al tipo de crecimiento que estaba desarrollando la ciudad hasta entonces $y$, por ende, en las condiciones de explotación del suelo imperantes, pero también las modificaciones que sufrieron los mismos (como la ampliación de los usos originales y los factores de ocupación -FOT y FOS- en determinadas áreas) indican la permanencia de intereses que socavaron en gran medida esas aspiraciones.

\section{Metodología}

El enfoque metodológico se asienta en la revisión de bibliografía, el análisis de documentos y la realización de entrevistas en profundidad. Fundamentalmente, se consideran los documentos que norman el planeamiento urbano y establecen las condiciones de ocupación y uso del suelo, como el Código de Planeamiento de 1980, pero también aquellos que supusieron cambios o modificaciones de estas condiciones, como las resoluciones del ejecutivo y, sobre todo, las Ordenanzas del Concejo municipal. Complementariamente, también se utilizan mapas y documentos fotográficos (imágenes aéreas) de diferentes periodos históricos para apoyar el análisis situacional y caracterizar la trama urbana de la ciudad. Por último, también se hace uso de fragmentos de entrevistas realizadas a informantes clave, como exfuncionarios y técnicos de planeamiento. Se espera de esta forma acceder a conocimientos pormenorizados de personas que, por su cargo o lugar que ocupan (u ocuparon), disponen de conocimientos específicos e información detallada del proceso de urbanización local.

\section{El nacimiento de la ciudad turística}

Las circunstancias que incidieron en el rumbo que tomó el crecimiento urbano de San Carlos de Bariloche deben remitirse a una trama de decisiones en las que destacadamente intervino el gobierno nacional en un contexto que no fue ajeno a la centralización de atribuciones de un Estado que aún debía consolidar sus fronteras territoriales. 
En principio, la creación de la Colonia agro-pastoril Nahuel Huapi en 1902 y la reserva de tierras para el trazado del casco urbano del poblado San Carlos se formalizó a través de un decreto del poder ejecutivo nacional. Esta decisión, como otras que sobrevendrían luego, no respondió a evaluaciones pormenorizadas que sopesaran las condiciones particulares del espacio físico local (Bessera, 2006): no se hicieron relevamientos climatológicos, edafológicos y/o ecológicos en el lugar, como tampoco se tuvo muy en cuenta el relieve característico de la región y,

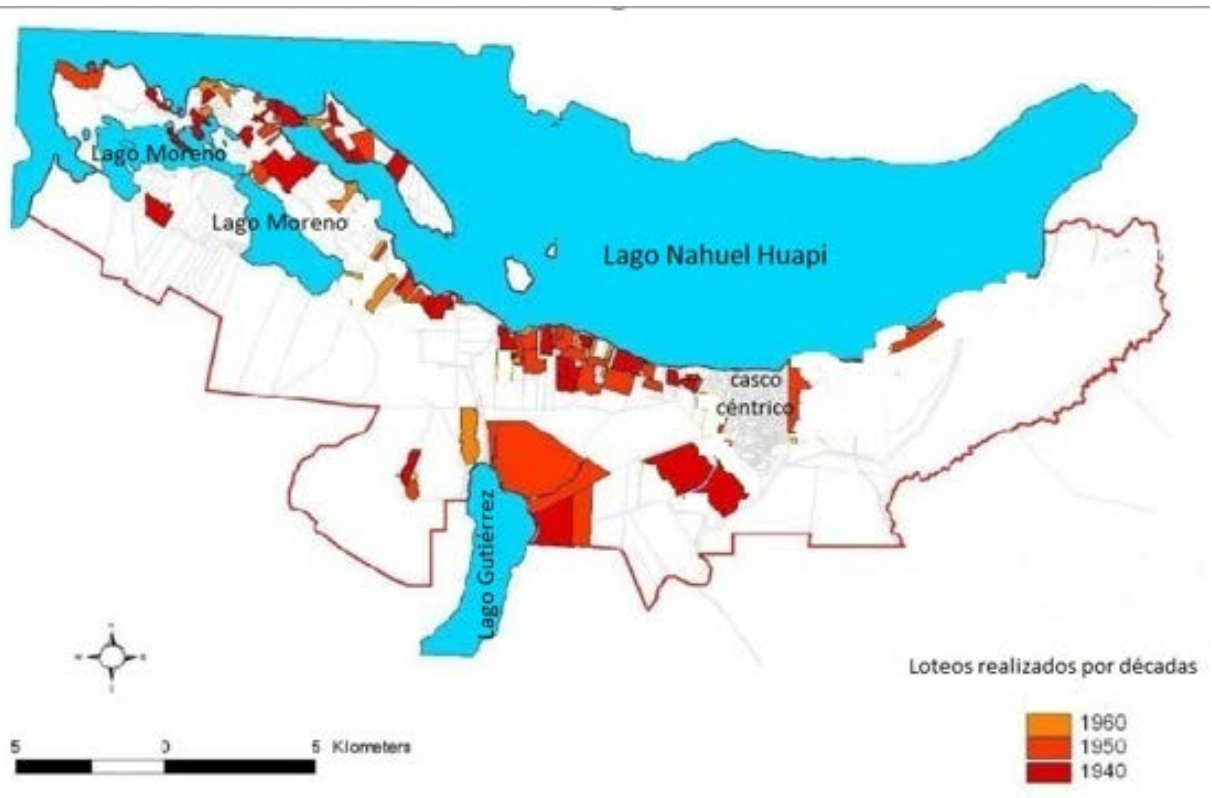
en consecuencia, la factibilidad de

Figura 1: Fraccionamientos realizados en San Carlos de Bariloche, 1940una economía agrícola-ganadera (más próxima a los llanos bonaerenses) como la que se pretendía promover en la región andina (Bessera, 2006). Sin embargo, en un contexto histórico en el que Argentina se alzaba como uno de los principales países productores y exportadores de bienes primarios, se naturalizaba esta orientación productiva. En el pensar de la elite gobernante, muchos de estos poblados (pertenecientes a la órbita federal de los antiguos territorios nacionales ${ }^{2}$ ) debían adecuarse y continuar por esta senda productiva. De esta forma, durante las primeras décadas del siglo XX, la actividad económica de la Colonia se basó en la producción agroforestal-ganadera y el intercambio comercial con Chile (Niembro, 2011).

Pero fundamentalmente, en aras de considerar la intervención del Estado nacional en la región, debe repararse en la gestión de gobierno de Parques Nacionales y la ubicación física de San Carlos de Bariloche en los límites espaciales del Parque Nacional Nahuel Huapi. Esta circunstancia incidió en su conversión turística y, asociado a ello, en el propio crecimiento de los márgenes territoriales de la ciudad. Fue a través de la

\footnotetext{
${ }^{2}$ Territorios que posteriormente se definirían bajo los límites políticoterritoriales de las actuales provincias. Una vez finalizada la campaña del desierto, el Estado nacional dispuso la subdivisión y reparto de las tierras obtenidas. Primero se creó la gobernación de la Patagonia y luego los territorios nacionales que en la actualidad comprenden a las provincias de Neuquén, Río Negro, Chubut, Santa Cruz y Tierra del Fuego (Méndez e Iwanow, 2001).
} 
refacción o construcción de nuevos hoteles. En definitiva, se trató de realizar el sueño ideario de la llamada "Suiza argentina" a través de la puesta en construcción de infraestructuras y provisión de servicios que acondicionaran un entorno pensado para el visitante.

Simultáneamente al inicio de esta serie de obras, que supusieron una profunda transformación de lo que hasta entonces era la ciudad, nacieron cuestionamientos en el seno de la naciente localidad andina, que observaban con recelo la influencia "externa" de la Nación en los destinos de la ciudad. Si bien al momento en que se debatió la Ley de Creación de Parques Nacionales (Ley 12.103) predominaba la posición que apuntaba a preservar la autonomía de los gobiernos municipales, la importancia geopolítica de Bariloche fue más determinante en la aplicación mermada de este principio (Méndez, 2010).

Creado en 1930, las autoridades municipales estuvieron tempranamente de acuerdo con el proyecto de provincialización de los territorios nacionales que en aquel tiempo comenzaba a debatirse (Méndez, 2010): en esos años Río Negro ya había superado la cantidad de 60.000 habitantes que se requería como condición mínima para acceder al estatus de provincia y contar con autonomía (Luorno, 2008; Ruffini y Blacha, 2013). Sin embargo, la provincialización de Río Negro recién se hizo efectiva en 1955; hasta ese año Parques Nacionales siguió decidiendo sobre el destino comercial de las tierras ubicadas en los límites jurisdiccionales de la ciudad, liberándolas al mercado y contribuyendo a estructurar el carácter desordenado y disperso de su traza urbana (Abaleron, 1995).

Mas el traspaso a la órbita municipal no supuso un cambio rotundo en relación con el modo de abordar la cuestión territorial y las políticas vinculadas a ella. En los años que continuaron a la provincialización, inercialmente se siguieron fraccionando tierras situadas en la cercanía o en costas de lagos, como el Nahuel Huapi y Moreno, y en lugares como península San Pedro, de preciada belleza visual. Asimismo, el Municipio también vendió muchos de los predios que Parques le había cedido para uso público (Méndez e Iwanow, 2001). Sin el resguardo proteccionista que podría suponer pertenecer a un parque nacional los loteos no solo se incrementaron, sino que además siguieron desvinculados del crecimiento demográfico y las necesidades de desarrollo urbano de la ciudad (Vapnarsky, 1983). Muchos de los adquirientes - frecuentemente personas que no vivían en Bariloche- no terminaban nunca de construir sus viviendas, lo que derivaba en un sinnúmero de terrenos vacíos y despoblados (Méndez e Iwanow, 2001). Además, como se fraccionaban sin ningún tipo de control y/o preocupación por la planificación del crecimiento urbano, no se los dotaba de los servicios básicos necesarios.

En las siguientes imágenes aéreas puede observarse el rumbo que tomó la mancha urbana entre los años 1940 y 1970. Se destacan las líneas de subdivisión, en calles y manzanas, de manera discontinuada en algunos sectores del área oeste y hacia el sur y sudoeste del ejido, donde posteriormente se formarían los denominados barrios "del alto" (Figura 2 y Figura 3).

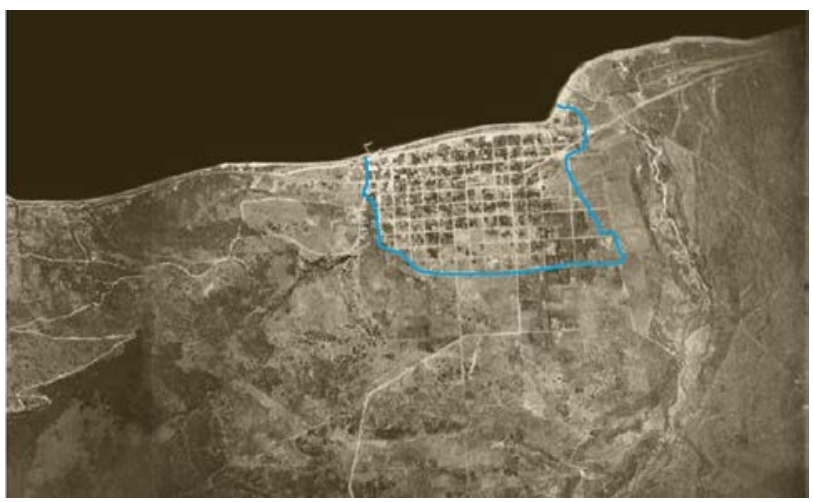

Figura 2: Casco céntrico. San Carlos de Bariloche, 1940.

Fuente: Elaboración personal sobre la base de imagen aérea obtenida de la Secretaría de Planeamiento del Municipio de San Carlos de Bariloche.

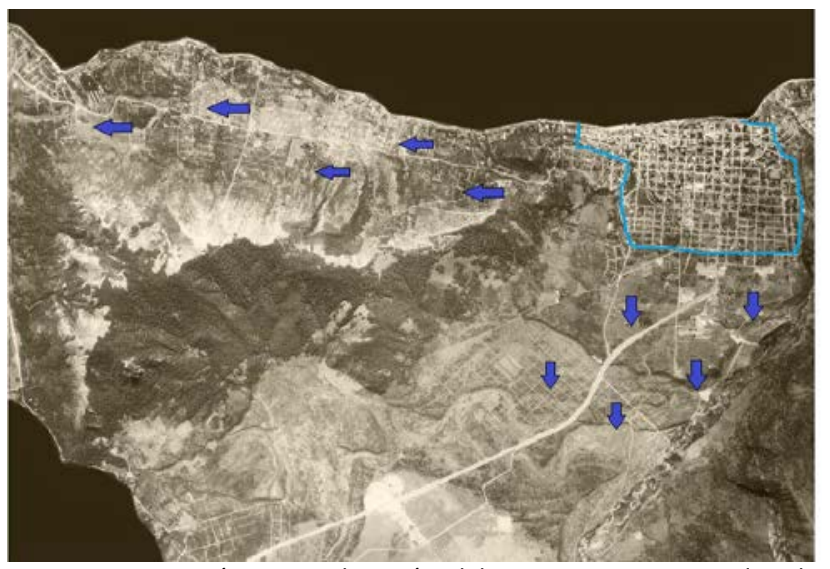

Figura 3: Casco céntrico y dirección del crecimiento. San Carlos de Bariloche, 1970.

Fuente: Elaboración personal sobre la base de imagen aérea obtenida de la Secretaría de Planeamiento urbano del Municipio de San Carlos de Bariloche. 
Prontamente la proliferación de fraccionamientos en el oeste, y la ya entonces ocupación dispersa del territorio, comenzaría a ser motivo de preocupación. A mediados de la década de 1970, Raúl Hernández, uno de los profesionales que ideó el Plan Director de 1979, señalaba el problema que entrañaba el crecimiento a expensas del bosque cordillerano y los espacios lacustres:

Sin lugar a dudas el desarrollo turístico de Bariloche se produjo sin ninguna pauta de plan o programa, o simple espíritu de conservación. En esta región se abrieron los caminos y calles sin ningún principio de trazado regional, se avanzó sobre bosques con loteos guiados por puros propósitos especulativos, se talaron áreas cubiertas de especies únicas en edad e imponencia, se levantó un poblado sin ningún signo de unidad expresiva capaz de guardar una forma arquitectónica coherente con su paisaje. Y lo que fue peor aún, se sobredimensionó el área de servicios urbanos -el ejido- que ninguna ni próspera municipalidad que fuere podría mantener sus servicios con un mínimo de calidad (Hernández, 1975, p. 3).

En una publicación anterior, el mismo Hernández (Hernández y Mochkofsky, 1974) presagiaba un escenario muy poco alentador respecto de las tendencias de crecimiento y su relación con la destrucción de la naturaleza. El uso intensivo y discrecional del espacio físico, vinculado con efectos propios de la actividad turística, planteaba serias interrogantes a su conservación, dado el progresivo avance de asentamientos urbanos sobre la naturaleza y la creación de nuevos accesos en áreas cuyo contacto debía ser restringido. De manera que hacia fines de la década de 1970 había un sobrado panorama de los efectos que el crecimiento desbordante tenía sobre el medio natural barilochense y las consecuencias nocivas a futuro si no se reaccionaba a tiempo. Este panorama era el que iba a afrontar el Plan Director a comienzos de 1980.

\section{El Plan urbano de 1979}

El Plan Director que se elaboró para Bariloche aludía entre sus objetivos a algunas preocupaciones relativas a las tendencias de crecimiento de la ciudad y sus principales consecuencias urbanas. Con anterioridad a dicho Plan, no se habían sancionado prescripciones generales ni mucho menos plexos normativos que integrados respondieran a un plan de ordenamiento del territorio de San Carlos de Bariloche. Aunque había habido estudios anteriores -como el Plan físico de Hardoy de 1964 y el de Odilia Suárez de 1977-, no tuvieron una traducción efectiva en la legislación urbana de la ciudad. Sí existía un conjunto de Ordenanzas que pretendían normar de manera parcial algunos aspectos edilicios y de ocupación del espacio, pero no respondían a un criterio unívoco que las encuadrara en un orden y sentido reconocibles ${ }^{3}$. Esto, en definitiva, tendía a la permanencia y continuidad de los problemas urbanos que se describieron más arriba y que evidenciaba la ciudad hacia la década de 1970: usos discrecionales del suelo que agravaban y hacían insostenible la conservación del entorno natural.

Hacia finales de la década, sin embargo, no pocas de estas cuestiones urbanas habían sido analizadas por distintos profesionales — como la ya mencionada Odilia Suárez- que habían advertido el peligro que encerraban en sí mismos los continuos fraccionamientos, los criterios indiscriminados que gobernaban sus aprobaciones y el factor turismo como elemento explicativo y propulsor del desbordante y disperso crecimiento de la ciudad. Raúl Hernández, arquitecto y sociólogo, era uno de estos profesionales que estudiaba las problemáticas urbanas de ciudades andinas como Bariloche y San Martín de los Andes en Fundación Bariloche. En virtud de estos antecedentes fue convocado, junto con un nutrido grupo de especialistas de distintas disciplinas, a idear el que posteriormente sería denominado Plan de Ordenamiento ambiental y Región Andino Patagónica, cuyas expresiones normativas constituirían el Código de Planeamiento y de edificación de 1980. Dicho Plan, formalizado a través de un acuerdo entre la Subsecretaría de Ordenamiento Ambiental de la Nación,

\footnotetext{
3 Uno de ellos era el Reglamento de construcciones de 1954 que, centrado en el perímetro urbano, dividía el área en seis zonas, definiendo los usos del suelo y los materiales permitidos para las edificaciones (Suárez, 1977). El otro derivó del trabajo de Hardoy que, sin haber llegado a aplicarse en su totalidad, sirvió de apoyo para el armado del Reglamento de subdivisiones aprobado en 1965 (Ordenanza 17-o-1965): "El Reglamento de subdivisiones de 1965 mantuvo el esquema general de las zonas propuestas por el 'Plan Físico' en el texto del ejido, pero readaptó, radicalmente, las superficies de parcelamientos permitidos. Así, zonas de fracciones de $150 \mathrm{Ha}$. Se redujeron a $2 \mathrm{Ha}$. o 1/4 de Ha., otras de $2 \mathrm{Ha}$. a 1/2 Ha., de $5 \mathrm{Ha}$. a 1.000 $\mathrm{m} 2$, y en las zonas de reservas montañosas se admitió la subdivisión mínima de 20 Ha." (Suarez, 1977, p. 152).
} 
la Secretaría de Planeamiento de la Provincia de Río Negro, y la Municipalidad de Bariloche, fue aprobado por Ordenanza en 1979 (Ordenanza 169-i-1979). Esta iniciativa comprendía, más allá de los objetivos generales de planificación y ordenación territorial, una intención inédita: poner freno a la depredación del entorno natural, enfatizando la limitación de actividades urbanas y el uso condicionado o directamente proscripto en ambientes cuyo cuidado y preservación se consideraba prioritario.

Las intenciones originales del Plan, expresadas fundamentalmente en el Código de Planeamiento de 1980 proponían, en cambio, estimular el crecimiento hacia el este de la ciudad, zona de estepa, de planicies y clima seco apto para edificaciones, y desalentarlos en aquellas zonas poco propicias para la congregación de asientos habitacionales: el sur y el oeste de la ciudad ${ }^{4}$. En efecto, entre sus metas figuraban reconocer el crecimiento y expansión del bosque y diferenciarlo de las actividades propiamente urbanas, es decir, poner freno a la mancha urbana que se expandía hacia el oeste por la Avenida Bustillo, lo que implicaba, además de los costos naturales, mayores erogaciones municipales para asegurar la prestación de servicios. Pero también, alineado a este objetivo, se buscaba desanimar el crecimiento urbano en otras áreas al sur de la ciudad, como la denominada "Pampa de Huenuleo", buscando conservarlas como áreas agrestes y rurales.

\section{La zonificación de la ciudad}

El Código de Planeamiento, en abierta concordancia a la preservación del medio ambiente que se preconizaba desde el Plan, dividía territorialmente la ciudad en áreas en las cuales la preocupación ecológica definía el criterio de distinción y el sentido de su aplicación. Así, se dispusieron las siguientes áreas de planeamiento: Área Urbana (UR), Área de Generación Ecológica (GE) (área suburbana), Área de Regeneración Ecológica (RE) (área

\footnotetext{
${ }^{4}$ Esta intención de planear la ocupación en determinados lugares y desalentarlas en otros es lo que impediría años más tarde, ya producida la ocupación espontánea e incontenible de las áreas "no queridas", la provisión de agua (de algunos servicios, como alternativa a "la provisión de agua") en la zona sur, de los barrios de más escasos recursos. Se argüía que el Plan Director no permitía el asentamiento poblacional en dicho sector (Méndez e Iwanow, 2001).
}

suburbana) y el área correspondiente a Villa Catedral (VC) (área suburbana).

Para cada una de estas áreas se definieron subáreas y se establecieron porcentualmente las funciones (o usos) que cada edificación podía tener, definiendo las funciones principales y complementarias de cada subárea. En términos generales, en el radio céntrico se admitían usos con fines residenciales, casas de familia o complejos edilicios de hasta treinta unidades, y usos complementarios a ellas como depósitos y estacionamientos. Pero también los usos comerciales y de servicios, particularmente en el casco céntrico, vinculados con la actividad turística de la ciudad: hoteles en sus más variadas dimensiones. La distribución funcional aprobada en la normativa respondía más bien al reconocimiento de un área urbana que ya se había consolidado como centro comercial y de atención de servicios relacionados con el turismo.

En las áreas de generación ecológica también se favoreció la construcción con fines residenciales, particularmente en las subáreas ubicadas al este del ejido, donde se deseaba orientar el crecimiento urbano, que recibieron indicadores urbanísticos altos (considerando el carácter suburbano del área). Mayormente se trataba de estimular la construcción de viviendas individuales que pudieran complementarse con construcciones destinadas a actividades de esparcimiento al aire libre, deportivas y/o de campamento. En otras subáreas directamente no se permitía la edificación de grandes hoteles ni edificaciones residenciales que excedieran la vivienda individual como unidad habitacional; dadas sus propiedades suburbanas, solo se permitían actividades agropecuarias y de extracción forestal que posibilitaran el resguardo del ambiente nativo. Una de estas subáreas era la Pampa de Huenuleo, en el sector sur-sudoeste de la ciudad, que recibió indicadores urbanísticos muy restringidos para edificar.

De todas formas, ninguna de las áreas mencionadas revestía el grado de emergencia ambiental comparable a las áreas que Hernández denominó de "regeneración ecológica.

Las áreas de regeneración ecológica eran las que mayor atención habían recibido, por el progresivo avance de la mancha urbana y la necesidad no solo de detener 
dicho crecimiento sino, más aún, de recuperar el bosque en algunas zonas, recuperar el paisaje y protegerlas de una mayor antropización; la mayoría de estas se ubicaban al oeste del casco urbano, en paralelo a la costa del lago Nahuel Huapi.

\section{Área de Implantación y Áreas de Reserva Ecológica}

Junto con otras propuestas como las prescripciones en torno a la trama circulatoria ${ }^{5}$ y la protección de la naturaleza ante emprendimientos arquitectónicos que pudieran dañarla, se destaca la materialización normativa de dos conceptos que buscaban regular el carácter de los fraccionamientos y el uso de la tierra: el Área de Implantación (AIM) y el Área de Reserva Ecológica (ARE). Ambos fijarían las condiciones de ocupación de los nuevos asentamientos en subdivisiones ya existentes y en terrenos por subdividir. EI AIM refería al área de un predio dado destinado a la edificación y a los objetos arquitectónicos aledaños que funcionalmente la complementaran. Esta área representaba un segmento del predio que variaba de acuerdo con su ubicación: en el área urbana, y de manera uniforme, representaba el $100 \%$, mientras que, en las áreas suburbanas, donde verdaderamente afectaba su variación y urgía conservar las masas boscosas y otras cualidades naturales propias de la ciudad y la región, este porcentaje tendía a ser menor en función de cada área y subárea $y$, relativamente, a medida que aumentaba el tamaño de cada predio. Así, mientras que el Factor de Ocupación del Suelo (FOS), que mide la proporción que existe entre el área de edificación propiamente dicha y la superficie del predio, en el área urbana alcanzaba dos tercios de lote (66\%), en las áreas suburbanas el FOS máximo permitido -en las subáreas en las que menos se desalentaba la ocupación- era del 33\%. De igual manera, en las áreas urbanas, junto con la altura, se permitía una mayor cantidad de pisos edificables (más de cuatro), como

\footnotetext{
${ }^{5}$ El Código de Planeamiento buscaba que, en las arterias primarias, como Avenida Bustillo y Avenida de Los Pioneros, que son las principales redes viales de conexión del centro al oeste, no se permitiera el estacionamiento a la veda del camino. En orden a ello, los locales comerciales, conociendo que podían incentivar ese tipo de estacionamiento, debían ubicarse al interior de los barrios, pero no sobre estas Avenidas. Además, en la arteria principal de la ciudad, la mencionada Avenida Bustillo, las construcciones debían guardar una medida de retiro de 10 metros, y en los sectores ubicados más al oeste hasta de 15 (desde arroyo Gutiérrez hasta Circuito Chico) y 25 (Circuito Chico).
}

también la construcción de torres en el subárea correspondiente al microcentro. En el área suburbana, en cambio, el Factor de Ocupación Total (FOT) era mucho más restringido: solo en algunas subáreas, y en predios de gran superficie (que alcanzaran los 5.000 metros cuadrados), se podía construir como máximo poco más de cuatro pisos de tres metros de altura cada uno.

Con la invención de las Áreas de Reserva Ecológica (ARE) se declaraba abiertamente la ambición conservacionista del Plan Director, complementándose con el AIM en sus dos versiones: el Área de Reserva Ecológica Externa (AREE) y el Área de Reserva Ecológica Interna (AREI). EI AREE era un requisito con el que debían cumplir los terratenientes para poder subdividir: se presentaba como un área de preservación natural externa a la creación de nuevos predios y la implantación de futuros asentamientos. En este sentido, el AREE se constituyó en una importante limitante para los fraccionamientos que se quisieran realizar, sobre todo en áreas suburbanas que todavía no habían sido loteadas (eran contadas las subáreas urbanas en las que se solicitaba AREE). En efecto, el Código de Planeamiento permitía subdividir, aproximadamente, solo el $30 \%$ de los predios, además de otras exigencias vinculadas a la dotación de servicios; el 70\% restante debía formar parte del $A_{R E E}{ }^{67}$. Si se tiene en cuenta que este $70 \%$ era intocable y solo se podía urbanizar en el 30\% del predio original, y al que además había que restarle calles, reserva fiscal y espacios verdes, la ecuación no era muy convincente para los propietarios y los grandes desarrolladores urbanos. Dado que la renta del suelo solo tiene razón de ser y emerge ante la posibilidad de usufructuar de la mejor manera posible la tierra por el capital, la exigencia del AREE definía un objetivo conservacionista que, reduciendo los márgenes de explotación, desalentaba nuevos fraccionamientos y, por ende, la incorporación de suelo urbano pasible de

\footnotetext{
${ }^{6}$ En las subáreas urbanas en las que se prescribía la exigencia de AREE esta relación era ligeramente menos dispar.

7 La situación dominial que se planteaba en el Código respecto de esta área era confusa. Pertenecía al o a los propietarios del área subdividida pero no se podía disponer de ella más que como área de reservorio ecológico que debía preservarse obligatoriamente. Un parte de su suelo podía utilizarse como centro de servicios comunitario, pero era un porcentaje mínimo de su superficie. Resultaba así un área verde no pública que debía mantener los atributos naturales previos a la subdivisión; esto en la práctica derivó, a menos que mediara la voluntad del o de los propietarios para su protección y cuidado, en su abandono.
} 
percibir renta. En consecuencia, esta medida suponía cuestionar la lógica especulativa de la adquisición de la tierra, poniéndole un freno a las continuas subdivisiones $y$ al valor y reservorio de inversiones que significaba tener una propiedad inmueble en Bariloche.

El AREI, en tanto, hacía referencia a la preservación de áreas naturales al interior de lotes ya subdivididos del área suburbana, esto es, al interior de asentamientos que, además del AIM y los retiros laterales y frontales, debían preservar un sector de reserva natural acorde al entorno del lugar. Por ejemplo, en un lote suburbano ya subdividido de 1.000 metros cuadrados podía corresponderle un AIM aproximado de 400, 240 o 200 metros cuadrados (según cada subárea y de acuerdo al criterio de preservación expresado normativamente en el Código de Planeamiento que debían respetar los nuevos asentamientos); descontando el AIM y los retiros laterales y frontales, el resto de la superficie del predio debía destinarse a AREI (Figura 4).

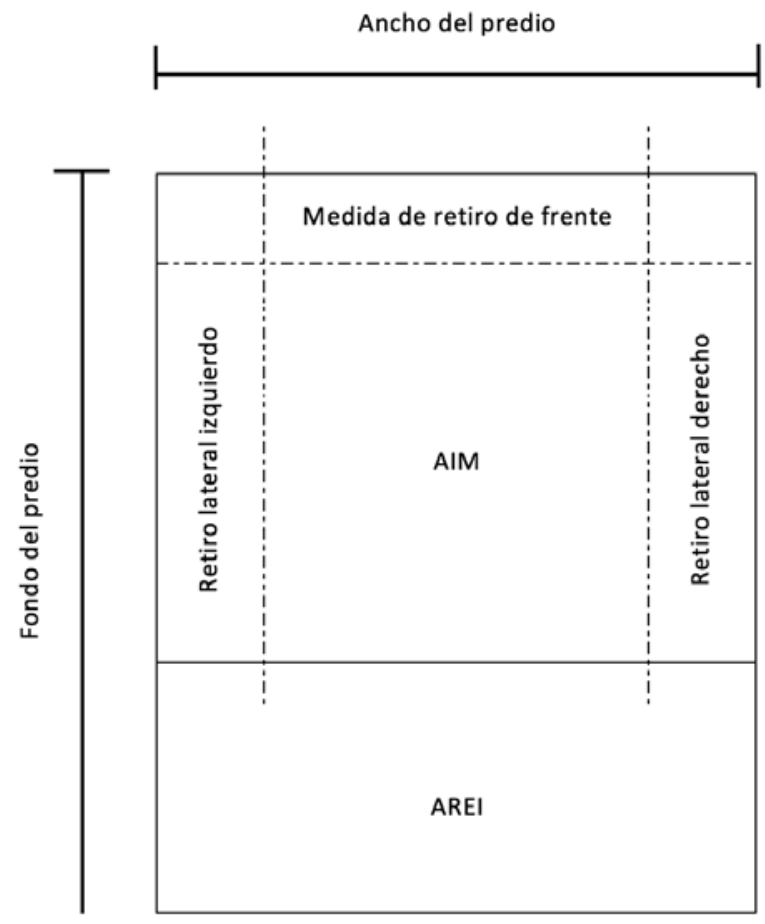

Figura 4: Área de Implantación de la edificación, retiros de superficie y Área de Reserva Ecológica Interna en un predio subdividido. Modelo prototípico.

Fuente: Elaboración personal en base al Código de Planeamiento de 1980.
De manera que, al igual que el AREE pero en predios ya subdivididos, el AREI también limitaba las capacidades explotables de la tierra, al menos en relación a la superficie edificable. La preservación del medio natural autóctono, o su recuperación, al interior de cada predio en las áreas suburbanas suponía también, como el AREE, recortar la indiscriminada tendencia de hacer de la tierra barilochense un puro objeto de valor.

\section{Modificaciones iniciales}

Luego de sancionados el Código de Planeamiento y de edificación, en el ocaso de la dictadura militar y durante el iniciático auge democrático, se aprobaron dos Ordenanzas, la 5 (5-i-1983) y la 6 (6-i-1983) de 1983 que, además de ampliar y brindar detalles acerca de la implementación de algunos artículos, significaron a la postre cambios medulares en la aplicación de dichos códigos, particularmente el de planeamiento.

Las principales modificaciones referían a la definición del ARRE y los criterios de subdivisión y magnitud de las parcelas a subdividirá, atendiéndose así demandas de sectores inmobiliarios que durante tres años habían esperado cambios en la normativa que, en muchos casos, so pretexto del contexto dictatorial en el que fue implementado, denunciaban las restricciones que el Plan Director les imponía.

La Ordenanza 5, que es la que modificaba algunos artículos del Código de Planeamiento, establecía que las cesiones de tierra correspondientes a circulaciones vehiculares, áreas verdes y de reserva fiscal podían formar parte del AREE. Un propietario no estaba obligado a ceder parte de la tierra que le habían permitido subdividir para cumplir con estos requisitos, sino que la podía sustraer de aquel. Esto en definitiva implicaba, por un lado, la reducción de la superficie destinada a preservar el patrimonio natural propio de la región y, por otro, el aumento de hecho de la superficie subdividida, al no tener que restar la superficie correspondiente a las cesiones obligatorias. La Ordenanza además especificaba los límites de recuperación de la costa del Lago Nahuel Huapi que en el Código de 1980 no habían sido precisados. Al hacerlo dividía el subárea original UR/E en UR/E1 y UR/E2, deshaciendo con ello el objetivo regenerativo y conservacionista del código. Esta última adquiría categoría de subárea residencial II, cambiando 
sustancialmente sus indicadores urbanísticos, e incorporando normas de subdivisión y construcción en altura menos restrictivas que no solo la asemejaba a otras subáreas urbanas de la ciudad, sino que al apartarla del destino conservacionista inicial "mejoraba" sustancialmente las condiciones de explotación de los predios allí ubicados.

En todas las subáreas de recuperación ecológica RE/D se incrementó un $25 \%$ la superficie del área de implantación (AIM) y un $15 \%$ la superficie máxima a construir en aquellos predios que contaran con electricidad, agua corriente y calles abiertas ${ }^{8}$. También, a los lotes que disponían de estos servicios se les aumentó considerablemente la cantidad de usos posibles (originalmente se podía edificar con fines exclusivamente residenciales y solamente viviendas individuales).

En cuanto a la magnitud de las parcelas a subdividir, se modificaban los mínimos de las parcelas resultantes en el área urbana: de un mínimo que era de $2.500 \mathrm{~m} 2$, cambiaban a 2.000 y 1.500 m2, según la subárea. En otros lugares cercanos al centro que debían definir AREE si las dimensiones del predio sobrepasaban los $2.500 \mathrm{~m} 2$ al momento de subdividir, se les concedió un límite máximo mayor, de entre 5.000 y 10.000 m2, según la subárea, para no tener que hacerlo. También se redujeron las medidas de retiro en las construcciones de las principales calles y rutas de la ciudad, específicamente en buena parte de sus conectores turísticos. Además, comenzaron a ganar terreno las solicitudes de excepción a la normativa, sea porque se deseaba edificar más allá de los factores de ocupación que autorizaba el código, o bien, porque se querían establecer usos no contemplados (muchos de los cuales, como ya se mencionó, existían de hecho) en áreas en las que, justamente, para desalentar su ocupación se los había prohibido o acotado rigurosamente su autorización. Sin embargo, estas excepciones lejos de corresponder a hechos puntuales que las definieran e

\footnotetext{
${ }^{8}$ Según lo recogido en algunas entrevistas, el Código de Planeamiento no se constituyó en modo alguno como elemento proscriptor en la dotación de tales servicios. Es decir, su comparecencia normativa no fue un obstáculo para la provisión de electricidad, agua y calles. De hecho, muchos vecinos comenzaron solicitando el cableado del servicio eléctrico a la Cooperativa de electricidad de la ciudad y luego demandaron el resto de los servicios y la apertura de arterias al Estado municipal. La organización de muchas juntas vecinales debe su fortaleza, en gran medida, a estos "hechos fundantes", a la tenencia de lotes sin servicios ni calles (Mandrini, 2010 y 2012).
}

identificaran como tales comenzaban a mostrar signos de un generalizado y regular incumplimiento con la normativa.

Se agregaba además el hecho de que muchos barrios, cuyo fraccionamiento se había decidido varios años antes de que el Plan entrara en vigencia, protagonizaban procesos de crecimiento en subáreas cuya ocupación originalmente se había pretendido desalentar. Este era el caso del barrio El Frutillar, situado en una subárea de generación ecológica, Pampa de Huenuleo, que en principio se quería destinar a actividades agropecuarias y/o forestales. Este barrio, lejos de reconvertirse, comienza a crecer notoriamente durante toda la década de 1980: en 1985 se incrementan las frecuencias diarias del transporte público de pasajeros (resolución 217-i-85) y se establecen sus límites territoriales. Estos hechos, junto con el reconocimiento municipal de su junta vecinal al año siguiente (resolución 44-i-86), otorgándole personería jurídica, daban muestras de la consolidación del barrio y sus dimensiones poblacionales. Circunstancias todas que contribuían a la urbanización de una zona que originalmente había sido pensada como suburbana, y alentaba, por cercanía e infraestructura, el crecimiento demográfico del resto de la subárea.

\section{Hacia el ocaso del Plan Director}

Transcurridos seis años desde la sanción del Plan Director, y como justificativo ante las excepciones otorgadas y el crecimiento de casos que no se ajustaban a lo sancionado, el Municipio propone evaluar los "casos especiales" (que supuestamente no contradecirían los objetivos ambientales y conservacionistas del Plan Director) por la Comisión de obras y servicios públicos, formada a tal efecto a través de la sanción de la Ordenanza 10 de 1986 (10-c-1986). Sin embargo, las excepciones al código continuarían: en el área urbana se siguieron aprobando construcciones que no respetaban el tercio libre que debían dejar las edificaciones (resoluciones del ejecutivo $365-\mathrm{i}-88$ y $492-\mathrm{i}-88$ ).

También en el área suburbana continuaban diluyéndose los objetivos tendientes a detener el crecimiento hacia el oeste del ejido urbano. Originalmente se habían otorgado indicadores urbanísticos altos a una subárea casi consolidada que abarcaba desde el casco céntrico hasta el kilómetro ocho. 
Traspasado ese límite, se pretendía evitar la proliferación de asentamientos humanos para el resto de las subáreas, que recibieron factores de ocupación muy bajos y usos lo suficientemente acotados como para desalentarlos. En orden a esto, la intención del Plan era que los centros de servicios y los comercios se ubicaran al interior de asentamientos ya consolidados y no sobre los márgenes laterales de los principales conectores viales, puesto que de este modo no solo se facilitaba el flujo de tránsito, sino que también se contribuía a desalentar la expansión suburbana (mediante la obstaculización del acceso a bienes y servicios de primera necesidad). Sin embargo, contrariando la intención del Plan Director, en 1987 el Municipio habilitó el uso comercial y de servicios en los predios ubicados al costado de los principales conectores viales que comunican al oeste (Avenida de Los Pioneros y Avenida Bustillo) que no contaran con acceso a través de arterias secundarias (Ordenanza 31-c-1987). De nuevo, entre los considerandos se señalaba la circunstancia de que ya existían - de hecho- actividades dedicadas al comercio y/o a los servicios turísticos en esas áreas. Se argumentaba que:

la tendencia espontánea detectada entre otros hechos, por las muchas solicitudes presentadas a la Secretaría de Obras Públicas, es la instalación de actividades comerciales, turísticas, de esparcimiento etc., precisamente sobre las vías principales de circulación, que son las dotadas de mejor infraestructura de todo tipo, tránsito de público y comercialmente más favorables (Ordenanza 31-01987).

La expansión turística también aparecía en el centro de las argumentaciones, revalidando el perfil turístico de la ciudad y su potestad ante cualquier otra razón de orden urbano: el acceso cómodo e inmediato de los turistas a los lugares de aprovisionamiento lo justificaba.

En poco tiempo las continuas modificaciones que erosionaban al Plan Director comenzaron a sentar las bases de su sustitución. En 1991 el Concejo Municipal encomendó realizar un riguroso estudio del Código de Planeamiento a la comisión de obras y servicios públicos que, junto con una propuesta de reformulación (Municipalidad de San Carlos de Bariloche, 1992), derivaría en un conjunto de postulados orientados a elaborar un nuevo código. Al año siguiente el propio
Concejo Municipal se haría eco de algunas de las conclusiones a las que arribaba el citado estudio señalando la extendida suburbanización de la ciudad y la subutilización de las tierras fraccionadas. Se estimaba que gran parte de las parcelas loteadas no habían sido ocupadas, especialmente en las áreas suburbanas donde se constaba que solo en unas pocas parcelas se estaba construyendo y/o contaban con avisos de obras, lo que presuponía que la gran mayoría de las parcelas estaba siendo retenidas como baldíos con fines especulativos. De acuerdo con las pautas de crecimiento poblacional calculadas, se estimaba que la ciudad podía albergar, aproximadamente, hasta un millón de habitantes (Bariloche en ese entonces contaba con una población de 90.000 habitantes).

Esta preocupación por la extendida suburbanización, la baja densidad poblacional y la ocupación dispersa de sus habitantes, que conllevaba elevados costos en infraestructura y prestación de servicios, terminaría siendo plasmada en la Ordenanza 70 de 1992 (70-cm1992) en la que se declaraba la autoridad del Concejo Municipal para decidir la aprobación de nuevas subdivisiones hasta que un nuevo código entrara en vigencia. En sus argumentos señalaba que la normativa de los códigos actuales no había logrado subsanar las tendencias observadas. Sin embargo, nada decía acerca de las modificaciones y excepciones que habían tenido los mismos, las cuales contribuyeron a alentar esos procesos $^{9}$.

En tanto, las labores de la comisión de asesoramiento junto con su homónima de la Secretaría de Obras Públicas y Planeamiento del Consejo Municipal continuaron señalando la compleja trama normativa de los códigos de planeamiento y edificación, considerando los cambios que habían atravesado desde 1980, y la dificultad que envolvía su interpretación en

\footnotetext{
${ }^{9}$ La Ordenanza fue en un principio vetada por el Ejecutivo (857-i-1992) al interpretar que este poder debía arrogarse la atribución de resolver estas cuestiones. La resolución señalaba que la normativa para aprobar las subdivisiones que se expresaban en la Ordenanza tenían que ver con bases y fundamentos indicados en el Código de Planeamiento y que, en consecuencia, era una atribución del Ejecutivo aprobar las subdivisiones de acuerdo a la normativa existente. Aun así, con el voto de al menos dos tercios de los ediles presentes, de acuerdo con lo establecido por carta orgánica, la Ordenanza 70-cm-1992 fue ratificada y aprobada por resolución por el presidente del Concejo. Lo que también se ratificaba era la importancia de decidir sobre algo tan caro a los intereses de los propietarios inmobiliarios, y a la dinámica de este sector, que suscitaba pugnas entre los poderes Ejecutivo y Legislativo.
} 
apreciaciones muchas veces disímiles y contradictorias. Esta búsqueda de claridad y simplificación normativa condujo, al menos hasta la aprobación del nuevo código urbano en 1995 a un conjunto de concesiones materializadas en la Ordenanza 82 de 1992 (Ordenanza 82-cm-1992). En ella se flexibilizaba una serie de patrones urbanísticos: en el área urbana se toleraban las construcciones que habían superado ciertos límites y la redistribución del trazado del área libre reglamentaria, en tanto y en cuanto se integrara a la retícula urbana y sus usos. Concesiones de esta índole también se hacían en las áreas suburbanas: se admitía la asimilación del FOS al AIM siempre y cuando lo justificara el carácter de la actividad (por ejemplo, religioso, salud, educación, deportes). Asimismo, en relación, al FOT se fijaba un aumento del $10 \%$ de los valores establecidos, también, siempre y cuando los emprendimientos ofrecieran razones de diseño o funcionales que lo justificaran. Lo que no aclaraban estas medidas era el criterio que debía decidir acerca de su "funcionalidad" y, además, si el tipo de actividad era razón suficiente para establecer esos cambios. En cuanto a los usos, se buscaba asimilar aquellos que no estaban contemplados originalmente por el código, siempre y cuando fueran compatibles con la subárea de planeamiento y el carácter del sector; esto, en resumidas cuentas, significaba avalar el espontáneo florecimiento de usos que la normativa, todavía vigente, expresamente prohibía ${ }^{10}$. De manera que poco a poco, en el marco de la discusión mayor por el cambio de código, las modificaciones en la normativa urbana daban cuenta que el crecimiento de la ciudad lejos había estado de ser regulado por el Plan Director.

A ello también comenzaron a sumarse problemas de índole habitacional que hacia fines de la década de 1980 no solo comenzaban a ser cada vez más gravosos, sino que incluían en muchos casos la desatención de la normativa establecida. Efectivamente, aunque a mediados de la década de 1980 se había dispuesto la regularización de ocupaciones en tierras municipales (Ordenanza 6-o-1986), es a inicios de los años de 1990 cuando los problemas habitacionales de la población

\footnotetext{
${ }^{10}$ Esta Ordenanza, que luego sería abrogada con la creación del Consejo de Planificación Municipal en 1994 (Ordenanza 418-cm-1994), respondía a comportamientos reiterados de muchos propietarios que, recluidos en cierta cultura patrimonialista local, procedían a construir sin el mayor apego a la normativa imperante.
}

empiezan a tomar cada vez mayor estado público. En esos años se crea el Fondo Municipal de la vivienda (Ordenanza 123-cm-1992), que luego sería sustituido por otras iniciativas tendientes a tratar el mismo problema. La falta de accesibilidad al suelo y a la vivienda eventualmente impactaría en la modificación de algunos indicadores urbanísticos de la zona sudoeste que inicialmente el Plan Director quería mantener de baja ocupación. Así es como se modifican, por razones de interés social, las normas de uso del suelo para permitir el fraccionamiento del barrio que hoy se conoce como Cooperativa 258 (Ordenanza 143-cm-1992). Junto a las 34 hectáreas, que más tarde se Ilamarían "Barrio Unión" y "2 de abril" constituirían un área de expansión urbana destinada a asentamientos residenciales que originalmente no se habían previsto ni deseado en el Código de Planeamiento de 1980. Muchas de las necesidades habitacionales de la población local se resolvieron facilitando los asentamientos humanos en tierras que en un principio se debía procurar no ocupar (o que, al menos, no conllevaran una carga que comprometiera la funcionalidad asignada). Así es como el Municipio decidió relocalizar a las familias que se encontraban ocupando la barda del arroyo Ñireco, un sitio de elevada peligrosidad (hacia el este del casco céntrico), junto con algunos vecinos del barrio "10 de diciembre". La relocalización consistió en la adjudicación de lotes en lo que originalmente eran las 34 hectáreas (Pampa de Huenuleo) y hoy son los barrios "Unión" y "2 "de abril":

Sorprendentemente, los lugares a los que las propias autoridades llevan a vivir las poblaciones de escasos recursos, según el Plan Director confeccionado por la propia municipalidad se definía como el sector donde no se debía permitir el asentamiento de la población por la altura sobre el nivel del mar (superior a la cota de 900 metros) a causa de las condiciones climáticas de la misma: zona de mucho frío y viento (Méndez e Iwanow, 2001, p. 202).

En paralelo a estas relocalizaciones, también se aprueba en el área sudoeste el fraccionamiento de nuevos terrenos para la construcción de 40 viviendas sociales, aledañas al plan de 400 viviendas que se proyectaban construir, asignándoles usos e indicadores urbanísticos de expansión urbana residencial no previstos en la normativa (153-cm-1992). Finalmente, 
algunas parcelas suburbanas pertenecientes al subárea de la Pampa de Huenuleo (GE/D) terminan redefiniéndose y en 1994 adquieren categoría urbana y residencial (UR/D). En una Ordenanza aprobada en ese año se terminaba reconociendo que:

El desarrollo urbano de la ciudad, a partir de la puesta en vigencia de los actuales Códigos de Edificación y Planeamiento, elaborados durante los años 1978 y 1979 en conjunto con la Subsecretaría de Ordenamiento Ambiental de la Nación y la Secretaría de Planeamiento de la Provincia de Río Negro, han demostrado, en cuanto a los nuevos asentamientos de carácter social promocionados por el Estado, y aquellos particulares, generalmente por iniciativa de
Se formalizaba así la transformación de ésta subárea, en la que ya existían barrios y se proyectaba la construcción de otros planes habitacionales, alejándose del perfil agrícola-forestal y de baja ocupación preconizado en el Código de Planeamiento de 1980. En este sentido, la Ordenanza aparentaba ser una cabal muestra de cómo la planificación terminaba mostrándose inocua y derrotada, como norma desafortunada, ante el avance de las fuerzas vivas de la ocupación. La síntesis final de este conjunto de hechos y modificaciones terminaría de producirse $-y$ legitimarse - al año siguiente con la aprobación parcial del Código urbano de 1995, pero eso ya constituiría otra historia.

\begin{abstract}
vecinos de escasos 0 medianos recursos agrupados en entidades intermedias, que la tendencia ha sido contraria a la planificación del desarrollo previsto hacia el Este de la ciudad.
\end{abstract}

Las características geográficas y topográficas del sector sudoeste del casco urbano (posibilidades ciertas de contar con servicios básicos de infraestructura; cercanía con el centro de la ciudad; disponibilidad de servicios sociales promovidos a través de los barrios construidos por IPPV; transporte, etc.) han sido determinantes para el asentamiento acelerado de ese sector. En la actualidad, la vocación de ser una zona urbana es ineludible, máxime cuando es la propia Municipalidad la que, tal vez obligada por las circunstancias, ha reconocido esta tendencia en su permanente accionar de gobierno (...) Esto da la pauta del convencimiento de los organismos técnicos municipales sobre la insoslayable tendencia de ese sector de la ciudad a un carácter residencial, con una densidad mayor que la propuesta actualmente por las normativas vigentes (Ordenanza 363-cm-1994) (Figura $\mathrm{N}^{\circ} 5$ ).

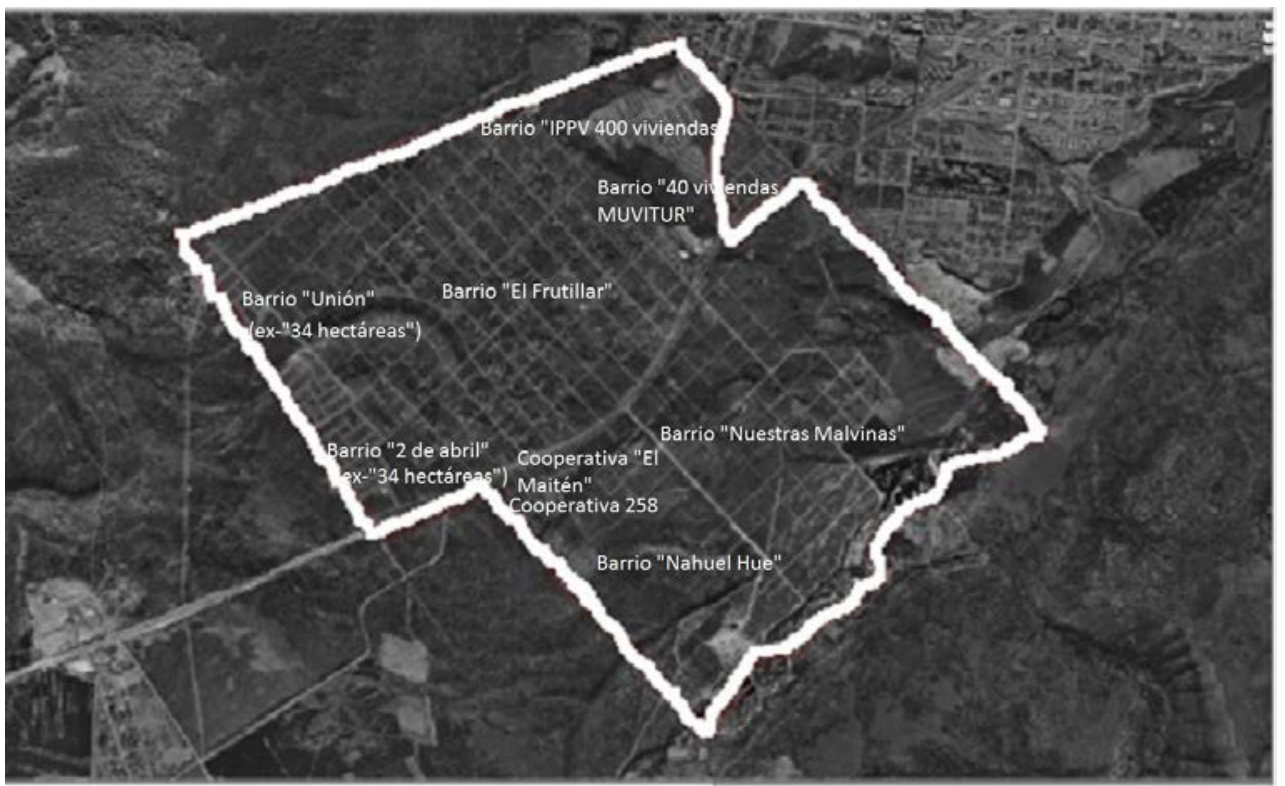

Figura 5: Barrios de la subárea Pampa de Huenuleo. San Carlos de Bariloche, 1994.

Fuente: Elaboración propia en base a imagen provista por el Instituto Nacional de Tecnología Agropecuaria (INTA) de Argentina.

\section{Conclusiones}

Los principales lineamientos del Plan Director estaban basados en la protección del entorno natural excepcional de Bariloche. Es por ello que el Plan buscaba principalmente limitar la expansión urbana hacia el sector más problemático, el oeste de la ciudad; pero también en el sector sur-sudoeste (en el que se pretendía una funcionalidad agrícola-forestal) se proponía restringir su crecimiento urbano. A su vez, y complementando esta intención, se deseaba estimular el 
crecimiento hacia el este, un sector estepario que por sus características semidesérticas se lo consideraba más propicio para la urbanización. A los fines de abordar la configuración urbana de la ciudad, estos objetivos apuntaban a contener la mancha urbana -que amenazaba con consolidar el crecimiento disperso de la ciudad - apostando a su re direccionamiento.

Ahora bien, desestimando el crecimiento hacia el este de la ciudad, que según uno de los entrevistados no fue viable por los intereses inmobiliarios de los pocos propietarios que eran dueños de las tierras de esa área, resta concluir qué fue de las intenciones del Plan Director que buscaban compactar la ciudad desalentando su crecimiento hacia el oeste y el sud-sudoeste. En este orden, pueden observarse dos procesos que tendieron a anular estas aspiraciones.

En primer lugar, se sostuvo el progresivo crecimiento y consolidación del oeste a lo largo de los denominados "kilómetros" (como se denomina a la extensión que cubre en esa dirección las Avenidas de Los Pioneros y, sobretodo, Bustillo, como principales conectores viales). A solo tres años de aprobado el Código de Planeamiento, la Ordenanza 5 de 1983 asignó nuevos usos e indicadores urbanísticos al conjunto de las subáreas RE/D, ubicadas en buena parte del sector oeste y en zonas aledañas a cuerpos de agua. La Ordenanza estipulaba que los propietarios de lotes que contaran con infraestructura y determinados servicios públicos podían hacer uso de estos beneficios, a los cuales accedieron porque ya contaban con alguno de estos servicios o porque se organizaron colectivamente y demandaron por ellos al Municipio ${ }^{11}$. Luego sobrevinieron otras ordenanzas que sobre aspectos más puntuales, y acaso más complementarios a esta última, como ser la habilitación de usos comerciales y de servicios sobre la Avenida Bustillo, también confluyeron en la consolidación urbanística de un área que el código originalmente pretendía preservar de la acción humana. En muchas de estas ordenanzas se aducía que el crecimiento del turismo ameritaba la habilitación de actividades acordes y la consolidación de infraestructuras adecuadas como si esa supuesta expansión, y la propia actividad en sí,

\footnotetext{
${ }^{11}$ Los casos más emblemáticos son, por ejemplo, barrios como casa de piedra y Pájaro azul entre los km 12 y 15 de Avenida Bustillo y, un poco más al sur, cerca del cerro Catedral, Villa los Coihues, que bordea los márgenes del lago Gutiérrez.
}

justificara la inexorable transformación de un Plan Director que, justamente, no buscaba otra cosa que contener los efectos no deseados del turismo ${ }^{12}$. En cambio, la admisión de nuevos usos que las Ordenanzas de modificación y excepción permitieron convalidó no solo un crecimiento de tipo difuso sino también la disposición de condiciones más ventajosas para la explotación de la tierra y la formación de mayores rentas de suelo.

En segundo lugar, el sector sur-sudoeste, sector en donde se ubican buena parte de los barrios más pobres de Bariloche -los barrios "del alto"-, también fue partícipe de un sostenido crecimiento, aunque sus tendencias de ocupación eran relativamente más recientes que en el oeste. Desgarrado por el pasaje de los vientos que lo golpean con singular rudeza y las fuertes nevadas, que arrecian con mayor intensidad y profusión que en otras áreas de la ciudad, este territorio presenta un entorno climático sumamente hostil. Por este motivo, históricamente su suelo ha sido de los menos valorados en toda la ciudad y uno de los más baratos. De hecho, la causa de por qué tantos asentamientos habitacionales se han propagado en los últimos años debe buscarse en la necesidad de la población de contar con suelo urbano accesible. La necesidad habitacional, el acceso a suelo y vivienda que los habitantes más desposeídos de la ciudad pudieran pagar, decidió en definitiva la incorporación de nuevas tierras con fines residenciales que originalmente no habían sido proyectados. Se crearon así viviendas y planes habitacionales en un área inclemente, de fuertes vientos y grandes nevadas, que simultáneamente facilitaban un acceso inmediato al centro de la ciudad. Incluso el propio Estado municipal desestimó lo preconizado en el Plan Director y en los códigos de planeamiento y edificación que lo expresaban, puesto que muchas de las necesidades habitacionales de la población barilochense se resolvieron concediendo nuevos patrones urbanísticos en estos suelos.

\footnotetext{
${ }^{12}$ De hecho, se podría afirmar que esto es lo que en primera instancia debería procurar un Plan Urbano: la disipación de los intereses sectoriales en beneficio del conjunto de la ciudad. Esto es, pensar la totalidad de una ciudad de manera integral, más allá de los intereses particulares de los habitantes que la componen: "Considerando que el urbanismo es producto de la vida en sociedad, la legislación urbanística, comprendida en el derecho administrativo, implica restricciones al dominio que procuran equilibrar el derecho de propiedad común con el derecho de propiedad privada" (Lolich, 2011, p. 108).
} 
Se puede concluir entonces que dos lógicas de urbanización se hicieron presentes como factores que inhibieron el cumplimiento del Plan Director implicando en paralelo la formación de rentas del suelo diferenciales y la consolidación de la ciudad difusa. En primer término, una lógica que puede identificarse en los propietarios y desarrolladores inmobiliarios que históricamente buscaron explotar las tierras de mayor atractivo turístico, y que es receptiva en buena medida a la penetración de sectores acomodados que conforman la demanda externa del mercado inmobiliario local. En segundo término, esta lógica se contrapone, acaso de manera

\section{Referencias}

Abaleron, C. A. (1995). Difusión espacial de la pobreza y destrucción del patrimonio natural: las dos caras de la moneda. EURE, 21(64), 61-74. Recuperado de http://www.eure.cl/index.php/eure/article/view/114 $\underline{9}$

Bessera, E. M. (2006). La Colonia Nahuel Huapi y los orígenes de la actividad turística en la región AndinoPatagónica. Trabajo presentado en "Historia de la Patagonia. 2das Jornadas" (CD-ROM), Universidad Nacional del Comahue, Neuquén. Recuperado de http://www.hechohistorico.com.ar/Trabajos/Jornada s\%20de\%20Roca\%20\%202006/Bessera\%20resumen.pdf\%202006/Bessera \%20resumen.pdf (obtenido el 03-12-2016).

Borja, J. (2007). Revolución y contrarrevolución en la ciudad global: las expectativas frustradas por la globalización de nuestras ciudades. Eure, 33(100), 35$50 . \quad$ Recuperado de http://www.scielo.cl/scielo.php?script=sci arttext\&pi $\mathrm{d}=\mathrm{S} 0250$ -

71612007000300003\&lng=en\&nrm=iso\&ignore=.html

Duhau, E. (2013). La división social del espacio metropolitano. Una propuesta de análisis. En Nueva Sociedad 243, 79-91. Recuperado de http://www.nuso.org/upload/articulos/3917 1.pdf cada vez más polarizada, a otra que nace de la falta de opciones y que responde a las necesidades habitacionales de gran parte de la población local. La crítica situación socio habitacional que comenzó a manifestarse en forma cada vez más patente a fines de la década de 1980 conllevó la obligada admisión de planes de viviendas en áreas de la ciudad que en un principio el Plan Director no había previsto. Una y otra lógica derivan, en definitiva, de la operatoria del mercado inmobiliario local y las prioridades de ocupación y explotación del suelo urbano que define la acumulación capitalista en una ciudad turística.

Hardoy, J. E. (1965). Plan físico para S. C. de Bariloche, 1964. Buenos Aires: Fundación Bariloche.

Herce, M. (2005). Urbanización, precios del suelo y modelo territorial: la evolución reciente del área metropolitana de Barcelona. EURE, 31(93), 35-51. Recuperado de http://www.scielo.cl/scielo.php?script=sci arttext\&pi $\mathrm{d}=\mathrm{S} 0250-71612005009300003$

Hernández, R. y Mochkofsky, G. (1974). Notas sobre un ejercicio de simulación del uso del medioambiente: el caso de San Carlos de Bariloche. San Carlos de Bariloche, República Argentina: Fundación Bariloche.

Hernández, R. (1975). Proyecto de estudio de pautas generales para el uso del medio-ambiente $y$ regulación urbana en San Martín de los Andes. San Carlos de Bariloche, República Argentina: Fundación Bariloche.

Indovina, F. (2007). Antes de la ciudad difusa. En La ciudad de baja densidad. Lógicas, gestión y contención. Barcelona: Diputació de Barcelona, Xarxa de Municipis.

Jaramillo González, S. (1999). El papel del mercado del suelo en la configuración de algunos rasgos socioespaciales de las ciudades latinoamericanas. Territorios: Revista de Estudios Urbanos Y Regionales, 2, 107-144. Recuperado de http://www.redalyc.org/articulo.oa?id=35700206 
Jaramillo González, S. (2009). Hacia una teoría de la renta del suelo urbano (2o edición). Bogotá D.C.: Ediciones Uniandes.

Lolich, L. (2011). Los planes urbanos y su relación con el paisaje cultural en zonas de frontera. Caso Bariloche, Patagonia argentina (1934-1979). En P. Núñez (Comp.), Miradas Transcordilleranas, (pp. 106-126). Argentina: IIDyPCA. Conicet-UNRN. Universidad Nacional de Río Negro. Recuperado de http://iidypca.homestead.com/PublicacionesIIDyPCa/ Nunez/Mlradas.pdf

Luorno, G. (2008). La provincialización de Río Negro. Interregno y conflictos de intereses nacionales $y$ locales. En G. Luorno y E. Crespo (Coord.), Nuevos espacios. Nuevos problemas. Los territorios nacionales (pp. 1-17). Neuquén: Educo-Universidad Nacional del Comahue-Universidad Nacional de la Patagonia San Juan Bosco-Cehepyc. Recuperado de http://historiapolitica.com/datos/biblioteca/tn05.pdf

Matossian, B. (2015). División social del espacio residencial y migraciones: el caso de San Carlos de Bariloche, Argentina. EURE, 41(124), 163-184. http://dx.doi.org/10.4067/S025071612015000400008

Medina, V. D. (2013). Rentas urbanas y alternativas de recuperación estatal. Aproximaciones al caso de San Carlos de Bariloche y la participación municipal en la renta diferencial. Quid, 16(3), 127-147. Recuperado de

http://publicaciones.sociales.uba.ar/index.php/quid1 6/article/view/1134

Medina, V. D. (2017). Las movilidades poblacionales y su impacto territorial en la estructura espacial de las ciudades turísticas. El caso de San Carlos de Bariloche. EURE, 43(129). https://doi.org/10.4067/s0250$\underline{71612017000200004}$

Meethan, K. (1997). York: Managing the tourist city. Cities, 14(6), 333-342. Recuperado de http://www.sciencedirect.com/science/article/pii/s0 264275197000243

Méndez, L. e Iwanow, W. (2001). Bariloche: las caras del pasado. Argentina: Manuscritos.
Méndez, L. (2010). Estado, frontera y turismo: historia de San Carlos de Bariloche. Ciudad Autónoma de Buenos Aires: Prometeo Libros.

Municipalidad de San Carlos de Bariloche (1992). Propuesta de Reformulación del Plan de Ordenamiento Ambiental de Bariloche: código urbano. San Carlos de Bariloche.

Niembro, A. (2011). El desarrollo (pendiente) de Bariloche: reflexiones a cien años de la comisión de estudios hidrológicos. Revista Pilquen, 13(14). Recuperado de http://www.scielo.org.ar/scielo.php?script=sci arttex t\&pid=S1851-31232011000100011

Otero, A. (2011). La dinámica territorial del turismo. En N. Wallingre y A. Villar (Comps.), Desarrollo y gestión de destinos turísticos (pp. 75-96). Bernal, Quilmes, Argentina: Ediciones Universidad Nacional de Quilmes.

Ruffini, M. y Blacha, L. (2013). La provincialización postergada de la Patagonia Argentina (1955-1958). Temas y Debates, 25, 59-81. Recuperado de http://www.scielo.org.ar/scielo.php?script=sci arttex t\&pid=S1853-984X2013000100003

Sánchez, J. E. (1991). El espacio geográfico. En J. E. Sánchez (Ed.), Espacio, economía y sociedad (pp. 325). Siglo XXI. Madrid.

Suárez, O. (1977). Plan de ordenamiento urbano San Carlos de Bariloche. Buenos Aires: Consejo Federal de Inversiones.

Topalov, C. (1979). La urbanización capitalista. México: Editorial Edicol.

Vapnarsky, C. (1983). Pueblos del Norte de la Patagonia 1779-1957. General Roca, Río Negro: Editorial de la Patagonia. 